\title{
Nelly Wolf, Le Menuisier et la blanchisseuse. George Sand et Zola
}

\section{Valentina Ponzetto}

\section{(2) OpenEdition}

1 Journals

\section{Edizione digitale}

URL: http://journals.openedition.org/studifrancesi/6696

DOI: 10.4000/studifrancesi.6696

ISSN: 2421-5856

\section{Editore}

Rosenberg \& Sellier

\section{Edizione cartacea}

Data di pubblicazione: 1 septembre 2010

Paginazione: 390

ISSN: 0039-2944

\section{Notizia bibliografica digitale}

Valentina Ponzetto, «Nelly Wolf, Le Menuisier et la blanchisseuse. George Sand et Zola», Studi Francesi [Online], 161 (LIV | II) | 2010, online dal 30 novembre 2015, consultato il 10 janvier 2021. URL: http:// journals.openedition.org/studifrancesi/6696 ; DOI: https://doi.org/10.4000/studifrancesi.6696

Questo documento è stato generato automaticamente il 10 janvier 2021.

\section{(c) (i) (9)}

Studi Francesi è distribuita con Licenza Creative Commons Attribuzione - Non commerciale - Non opere derivate 4.0 Internazionale. 


\title{
Nelly Wolf, Le Menuisier et la blanchisseuse. George Sand et Zola
}

\author{
Valentina Ponzetto
}

\section{NOTIZIA}

NELLY WOLF, Le Menuisier et la blanchisseuse. George Sand et Zola, in «Revue d'Histoire littéraire de la France», vol. 109, 2009, n 4, pp. 899-908.

1 Sand un falegname? Zola una lavandaia? Dietro l'apparente paradosso si cela un progetto di lettura di due celebri romanzi, Le Compagnon du Tour de France di Sand e L'Assommoir di Zola, come ritratto dello scrittore nei panni di un umile artigiano.

2 Nettamente suddiviso in due parti, una per ogni romanzo, legate fra loro dal medesimo presupposto iniziale, l'articolo si presenta infatti come una doppia illustrazione e decodificazione del rapporto metaforico che legherebbe la rappresentazione letteraria di un mestiere e di chi lo esercita ad una riflessione sulla lingua e sul rapporto dell'autore con il testo.

3 Così Nelly Wolf vede un'identificazione implicita di Gorge Sand nella figura idealizzata del falegname Pierre Huguenin, detto «l'ami-du-trait». La romanziera e l'artigiano condividono infatti un'educazione non scolastica, acquisita tardi, in maniera indipendente e libera dalla tirannia del greco e del latino, e un bisogno di riscatto da una condizione iniziale di oppressione e di inferiorità. Tuttavia l'autrice segnala in Sand un limite alla ricerca di un protocollo di scrittura veramente democratico poiché lo scrittore, in quanto appartenente ad un élite intellettuale, mantiene per lei un ruolo di controllo, di supervisione e di filtro sulla scrittura e l'oralità popolare.

4 Tale filtro ancora classico di riscrittura scompare nell'Assommoir, in cui Zola attribuisce all'esatta mimesi del linguaggio popolare, meticolosamente studiato nel Dictionnaire de la langue verte di Delvau, una fun-zione documentaria che tocca l'essenza stessa del romanzo naturalista. Nella descrizione delle diverse fasi del mestiere della lavandaia, dallo smistamento della biancheria sporca alla stiratura, Nelly Wolf identifica una 
simbologia del funzionamento della scrittura naturalista, che stilizza la lingua del popolo, ormai divenuta comune a tutti, per fabbricare un codice letterario.

5 Malgrado una certa impressione di artificio retorico, l'argomentazione, soprattutto nella parte dedicata a Zola, appare convincente e ben documentata da esempi testuali. L'articolo traccia così un breve saggio di sociologia dello stile dei due romanzi. 